\title{
Lipase-catalyzed production of lysophospholipids
}

\author{
Taha Mnasri, Josiane Hérault, Laurent Gauvry, Céline Loiseau, Laurent Poisson, Françoise Ergan \\ and Gaëlle Pencréac'h ${ }^{*}$
}

Mer, Molécules, Santé - EA 2160, Université du Maine - CeRiUM² - IUT de Laval, 15 rue des Drs Calmette et Guérin, BP 2045, 53020 Laval Cedex 9, France

Received 14 February 2017 - Accepted 6 March 2017

\begin{abstract}
Lysophospholipids, such as lysophosphatidic acid or lysophosphatidylcholine, are important bioactive lipids, involved in various normal and pathological cellular processes. They also have industrial and pharmaceutical uses such as emulsifiers or components of drug delivery systems. Lipases, which natural substrates are long chain triacylglycerols, are important biocatalysts for organic synthesis mainly due to their broad substrate specificity and their ability to display high catalytic activity in organic media. This paper describes the various lipase-catalyzed reactions implemented for the production of lysophospholipids. They include hydrolysis or alcoholysis of phospholipids and acylation of the glycerophosphoryl moiety. Special emphasis is made on our work dealing with the production of lysophospholipids rich in dososahexaenoic acid, an important dietary polyunsaturated fatty acid via the hydrolysis of phospholipids extracted from the microalga Isochrysis galbana.
\end{abstract}

Keywords: lipase / lysophospholipid / hydrolysis / esterification / docosahexaenoic acid

Résumé - Synthèse de lysophospholipides catalysée par des lipases. Les lysophospholipides, comme par exemple l'acide lysophosphatidique ou la lysophosphatidylcholine, sont des médiateurs lipidiques impliqués dans de nombreux processus cellulaires. Ils sont également employés au niveau industriel comme émulsifiants ou dans les formulations galéniques, par exemple. Les lipases, dont les substrats naturels sont les triacylglycérols à longues chaînes, sont des biocatalyseurs très utilisés en synthèse organique, du fait de leur large spécificité de substrats et de leur activité catalytique élevée en milieu organique. Cet article décrit les différentes approches développées pour la synthèse des lysophospholipides mettant en œuvre les lipases, à savoir l'hydrolyse ou l'alcoolyse de phospholipides et l'acylation de la partie glycerophosphoryle correspondant au lysophospholipide recherché. En particulier, nos travaux, portant sur la synthèse de lysophospholipides riches en acide docosahexaénoique par hydrolyse de phospholipides issus de la microalgue Isochrysis galbana, sont présentés.

Mots-clés : lipase / lysophospholipide / hydrolyse / estérification / acide docosahexaénoique

\section{Introduction}

Lysoglycerophospholipids (or lysophospholipids, LPLs) are glycerol-based lipids containing one fatty acyl moiety at either the $s n 1$ or $s n 2$ position and a phosphate group at the $s n 3$ position. Except for lysophosphatidic acid (LPA), the phosphate group is esterified to an alcohol or amino-alcohol (mainly choline, ethanolamine, inositol and serine) leading to various LPL species, such as lysophosphatidylcholine (LPC), the most abundant one in nature, or lysophosphatidylethanolamine (LPE). Depending on the acylated position, two isomers are distinguished, namely 1-acyl-2-lyso-phospholipid (or 2-LPL)

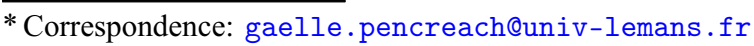

and 1-lyso-2-acyl-phospholipid (or 1-LPL). For example, the structures of 1-LPC and 2-LPC isomers are shown in Figure 1.

LPA has first attracted attention as an ubiquitous mediator in cellular signal transduction (Valentine et al., 2008; Lin et al., 2010). However, other LPL species have been studied since then and are also now recognized as essential bioactive lipids involved in a large variety of both normal and pathological processes such as carcinogenesis, neurogenesis, immunity, vascular development or regulation of metabolic diseases (Grzelczyk and Gendaszewska-Darmach, 2013). Moreover, LPLs circulate in the plasma mainly bound to albumin and their concentration can significantly vary in relation with some diseases. They are thus considered as potential biomarkers for the early detection of ovarian cancer (Fan et al., 2016) or colorectal cancer (Zhao et al., 2007). 


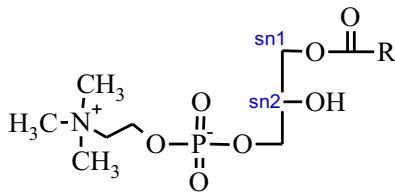

1-acyl-2-lyso-phosphatidylcholine (2-LPC)

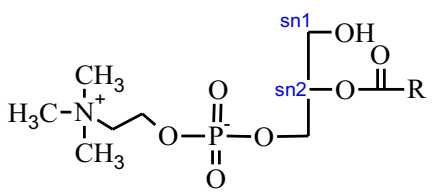

1-lyso-2-acyl-phosphatidylcholine (1-LPC)
Fig. 1. Structures of lysophosphatidylcholine isomers $(R=a c y l$ chain).

Interestingly, most often LPL effects are remarkably acyl chain-dependent, i.e. related to acyl-chain length and degree of unsaturation (Brkić et al., 2012; Rao et al., 2013). For instance, among the various species of LPCs in plasma, 16:0-, 18:1- and 20:4-LPC induce an increase of endothelial prostacyclin production in vitro (1.4-, 3- and 8.3-fold, respectively) although C18:2-LPC is inactive (Riederer et al., 2010). Moreover, several studies have contributed to show that LPLs are convenient carriers for optimal transport of docosahexaenoic acid (DHA, C22:6 $\omega 3$ ) to the brain where it plays a number of important functions (Bernoud et al., 1999; Lagarde et al., 2015). DHA-LPLs have also been proved to be antiinflammatory (Huang et al., 2010; Hung et al., 2011) and antiangiogenic (Tsushima et al., 2012) lipids.

LPLs have also industrial and pharmaceutical uses such as emulsifiers and wetting agents for the food-processing (Kasinos et al., 2014) and cosmetic industries (Yahagi et al., 2011), components of liposomes for use in drug delivery (Koklic and Trancar, 2012) and adjuvant in vaccines (Cmielewski et al., 2010).

Due to their diverse biological roles and industrial applications, efficient methods for production of LPLs are necessary. In literature, various chemical, enzymatic or chemoenzymatic ways for LPL synthesis have been described and reviewed (D'Arrigo and Servi, 2010; Pencreac'h et al., 2013). Enzymatic pathways, using lipases or phospholipases, are of particular interest due to their stereoselective activities although building the lyso-PL chiral structure is a crucial issue when using chemical routes. Moreover, enzymatic reactions usually occur under milder conditions, mainly lower temperatures, as compared to chemical reactions.

Lipases (triacylglycerol acyl hydrolases, E.C.3.1.1.3) are ubiquitous enzymes which natural function is to catalyze the hydrolysis of ester bonds in long chain triacylglycerols. They are widely distributed among animal, plant and microbial kingdoms. Lipases are classified into 2 groups regarding their regioselectivity: 1,3-regioselective lipases preferentially catalyze hydrolysis of ester bonds at the 1 and 3 positions in triacylglycerols, and non-specific lipases catalyze the hydrolysis of the three ester bonds similarly. Interestingly, in low aqueous conditions, such as in organic solvent, ionic liquid or supercritical $\mathrm{CO}_{2}$, microbial lipases also efficiently catalyze the reverse reaction, i.e. ester bond synthesis. Moreover, lipases display broad substrate specificity and catalyze a large number of various reactions (Kapoor and Gupta, 2012). All these reasons make lipases one of the most widespread biocatalysts used in biotechnological applications. Many lipases from bacterial and fungal sources are commercially available from several suppliers under either free or immobilized form.
Particularly, lipases are widely used in the field of enzymatic modifications of phospholipids. Indeed, they are efficient biocatalysts for hydrolysis of ester bonds (Haas et al., 1994; Hara et al., 1997; Gutiérrez-Ayesta et al., 2007) or acyl chain exchange in phospholipids (Haraldsson and Thorarensen, 1999; Vikbjerg et al., 2005).

This paper describes the various ways using lipases for the production of LPLs with special emphasis on our works dealing with the production of DHA-LPLs via hydrolysis of DHA-rich phospholipids extracted from the microalga Isochrysis galbana.

\section{Lipase-catalyzed deacylation of phospholipids}

LPLs can be produced via enzyme-catalyzed partial deacylation of phospholipids, i.e. hydrolysis of one of the two ester bonds of phospholipids. Most often, the enzyme used for this purpose is phospholipase A2 and the phospholipidic substrates are natural phospholipids, the so-called lecithins, from soybean (Aura et al., 1994), sunflower (Cabezas et al., 2012) or egg yolk (Kim et al., 2001). In these cases, the acyl chain released is the one linked to the $s n 2$ position due to the $s n 2$ regioselectivity of phospholipase $\mathrm{A} 2$.

However, in some cases, it is advantageous to deacylate the $s n 1$ position rather than the $s n 2$ position of phospholipids using 1,3-regioselective lipases. This occurs when phospholipids contain fatty acids with health or industrial benefit linked to the $s n 2$ position. The $s n 1$ specific deacylation therefore allows the production of 1-LPL rich in the desired fatty acids. Several studies have implemented this approach for the production of DHA-rich LPLs. Indeed, DHA moiety in DHA-containing phospholipids from natural sources is almost exclusively located at the $s n 2$ position (Farkas et al., 2000; Chen and Li, 2007). Thus, the 1,3-regioselective lipase from Rhizomucor miehei (Lipozyme RM-IM ${ }^{\circledR}$, Novozymes, Denmark) has been used to catalyze the hydrolysis of DHA-rich phospholipids extracted from squid skin (Ono et al., 1997; Tsushima et al., 2012) or from egg yolk enriched in DHA obtained from fish oil-fed hens (Ono et al., 1997; Hosokawa et al., 1998). In our laboratory, we have shown that I. galbana (strain 927/1, CCAP, Ambleside, UK), a well-known DHA-rich marine microalga, is a suitable source of phospholipids for the lipase-catalyzed preparation of DHA-LPLs. Indeed, in this microalga, $75 \%$ of the DHA contained in total lipids are contained in the phospholipidic fraction and DHA represents $50 \%$ of the total fatty acid profile of phospholipids. Moreover, DHA is actually located at the $s n 2$ position of the glycerol backbone (Devos et al., 2006).

In order to achieve lipase-catalyzed partial hydrolysis of DHA-rich phospholipids, the main challenge is to select a lipase that releases all acyl chains but DHA from the glycerol backbone i.e. which discriminates against DHA. Among twelve lipases tested, the immobilized lipases from Rhizopus oryzae (Lipase F AP-15 $5^{\mathbb{*}}$ ) and Mucor javanicus (Lipase $\mathrm{M}^{\mathbb{B}}$ ), provided by Amano Enzymes (Japan), efficiently catalyze ester bond hydrolysis in phospholipids with, however, low DHA release. Both lipases are 1,3-regioselective towards triacylglycerols although Lipase $\mathrm{M}^{18}$ may also slightly release some fatty acids from the $s n 2$ position (technical data sheets 
from the supplier). The time course of the reaction with Lipase F AP- $15^{\circledR}$ is shown in Figure 2 (from Devos et al., 2006). It can be seen that DHA ratio among total phospholipid fatty acids increased rapidly, from $50 \%$ to around $70 \%$ within the first $15 \mathrm{~min}$ of reaction, and afterwards more slowly to reach $77 \%$ after $3 \mathrm{~h}$ of reaction. Regarding DHA recovery, i.e. recovery of DHA initially present in phospholipids, a decrease was observed down to $85 \%$ during the first hour of reaction with no further modification with time.

Further experiments were performed in view to determine whether the DHA chain remains located at the $s n 2$ position or migrates spontaneously to the sn1 position as presumed. Indeed, 2-LPLs are thermodynamically more stable than 1LPLs and intramolecular acyl migration from the $s n 2$ to the $s n 1$ position was shown to readily occur (Plückthun and Dennis, 1982). In our case, a multi-step enzymatic method was developed to address this issue (Poisson et al., 2009). The LPLs produced by the selective hydrolysis of I. galbana phospholipids with Lipase F AP- $15^{\mathbb{B}}$ were further hydrolyzed using a phospholipase A2. No DHA release was observed proving that no DHA was attached to the $s n 2$ position in LPLs. The LPLs were then hydrolyzed using the Pseudomonas aeruginosa lipase (Lipase PS, Amano Enzyme Europe, UK),

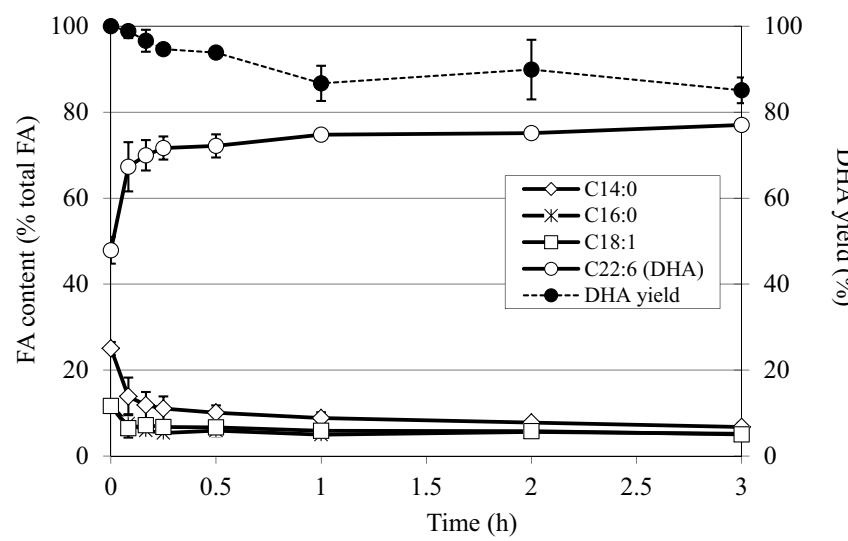

Fig. 2. Time course of DHA enrichment of LPC via selective hydrolysis of DHA-rich phospholipids from the microalga Isochrysis galbana. which is known to be non-specific (Devos et al., 2006). In this case, DHA was efficiently released proving that DHA had actually migrated from the $s n 2$ to the $s n 1$ position. Figure 3 represents the general scheme of 1,3-regioselective lipasecatalyzed hydrolysis of phospholipids, illustrated with phosphatidylcholine, taking into account the acyl migration occurring in the LPCs produced.

Interestingly, the observation that the Lipase F AP-15 actually discriminates towards DHA even though DHA chains migrate to the $s n 1$ position indicates that this lipase displays a clear typoselectivity against DHA.

\section{Lipase-catalyzed acylation of glycerophosphoryl moiety}

Besides partial hydrolysis of phospholipids, lipases have also been used to synthesize LPA, LPC and LPE via acylation of one of the two hydroxyl groups of glycerophosphatidic acid (GPA, disodium salt form), glycerophosphocholine (GPC) and glycerophosphoethanolamine (GPE), respectively. The reactions were implemented in low-aqueous environment in order to favour the synthesis reaction $v s$. the hydrolysis reaction. The acyl donors were either free fatty acids for direct esterification reactions (Han and Rhee, 1995; Virto et al., 1999; Kim and Kim, 2000; Hong et al., 2011) or fatty acid vinyl esters for transesterification reactions (Virto et al., 1999; Virto and Adlercreutz, 2000). Figure 4 represents, as an example, the scheme of GPC esterification with free fatty acids.

From these studies, it is clear that lipases, and more particularly immobilized lipases, are suitable catalysts for such reactions. For the esterification of GPC with free palmitic acid, two immobilized lipases, namely $R$. miehei lipase and Candida antarctica lipase B (Lipozyme RM-IM ${ }^{\circledR}$ and Novozym $435^{\circledR}$, respectively, Novozymes, Denmark, ) were shown to be efficient catalysts with $68 \%$ and $42 \%$ of GPC conversion to LPC, respectively (Kim and Kim, 1998). Among three free lipases tested for the same reaction, Aspergillus lipase (Lipase AP- $6{ }^{\circledR}$, Amano Enzymes, Japan) offered similar activity $(50 \%)$ as the immobilized lipases although the other two, namely $R$. oryzae lipase and $R$. niveus lipase (Lipase F-AP15 and Lipase $\mathrm{N}^{3}$, respectively, Anamo Enzymes, Japan) displayed lower activities (34-36\%). Hong et al. (2011) also compared several

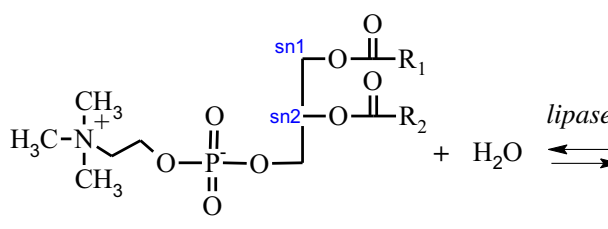

phosphatidylcholine

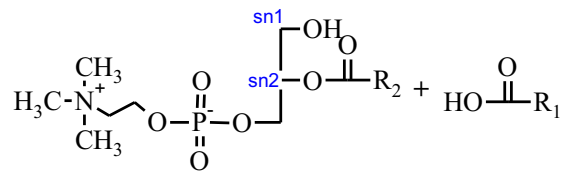

1-lyso-2-acyl-glycerophosphocholine

fatty acid

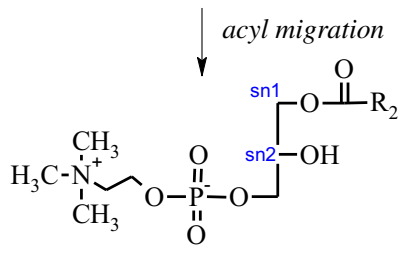

1-acyl-2-lyso-glycerophosphocholine

Fig. 3. Reaction scheme of 1,3-regioselective lipase-catalyzed hydrolysis of phosphatidylcholine. 


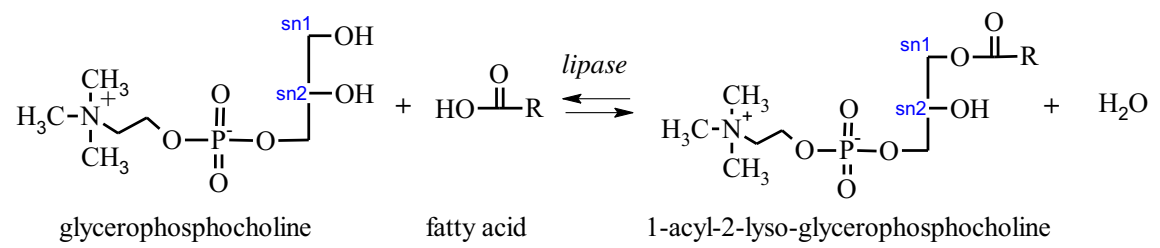

Fig. 4. Reaction scheme of 1,3-regioselective lipase-catalyzed esterification of glycerophosphocholine with free fatty acid.

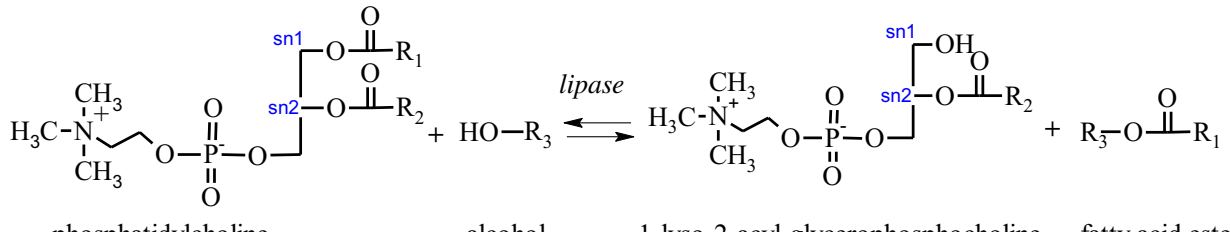

phosphatidylcholine

alcohol

1-lyso-2-acyl-glycerophosphocholine

fatty acid ester

Fig. 5. Reaction scheme of 1,3-regioselective lipase-catalyzed alcoholysis of phosphatidylcholine.

enzymes for the esterification of GPC with conjugated linoleic acids: three immobilized lipases (Novozym $435^{\circ}$, Lipozyme TL-IM ${ }^{\mathbb{B}}$, Lipozyme RM-IM ${ }^{\mathbb{R}}$ ), a free phospholipase A1 (Lecitase Ultra , Novozymes, Denmark) and a free phospholipase A2 (Lecitase 10L ${ }^{\circ}$, Novozymes, Denmark). Interestingly, the two phospholipases are less effective $(<10 \%$ GPC conversion) than the immobilized lipases in the reaction conditions used (approximately 40\%, 18\% and 15\%, respectively).

Regarding the implementation of these reactions, trials were first performed by mixing the substrates and the enzyme in various organic solvents commonly used as non-aqueous media for lipase-catalyzed reactions (Han and Rhee, 1995; Kim and Kim, 2000). It was observed that the esterification reaction proceeded very slowly, or even did not proceed at all depending on the solvent used, due to the insolubility of GPA (Han and Rhee, 1995) and GPC (Kim and Kim, 2000) in the solvent. Indeed, GPA and GPC are highly polar molecules nearly insoluble in organic solvents such as hexane, 2-methyl2-butanol or acetonitrile. Experiments have therefore been further performed in solvent-free systems in which the free fatty acids or fatty acid esters form the liquid phase. However, GPC solubilisation in these conditions was still not complete. Some solid GPC particles were still visible in the reaction mixture and they slowly solubilized as the reaction proceeded (Kim and Kim, 2000). Similarly, GPA was reported to form a separated gel phase or to be dispersed in the media depending on the fatty acid used (Virto et al., 1999).

In acylation reactions in low-aqueous environment, another crucial parameter is the water present in the reaction medium (Stergiou et al., 2013). Water is indeed essential to maintain the adequate hydration state of the catalyst for maximal activity. Moreover, in direct esterification reaction, water is a product of the reaction which can shift the equilibrium towards hydrolysis if not removed from the reaction medium. This is why, in studies dealing with the esterification of GPA or GPC, water amount is controlled by either performing the reaction in open reactors (Han and Rhee, 1995), under low pressure (Hong et al., 2011), adding a convenient co-solvent such as dimethylformamide (Kim and Kim, 2000) or buffering the water amount during the reaction by the use of salt hydrate pairs (Han and Rhee, 1998).
Regarding the acyl moiety of the synthetized LPLs, most are saturated chains. Capric (C10:0), lauric (C12:0), myristic (C14:0) and palmitic (C16:0) fatty acids (Han and Rhee, 1998; Kim and Kim, 2000) and their vinyl ester counterparts (Virto and Adlercreutz, 2000) have thus been studied as acyl donors. In comparison, to our knowledge, only one study has specifically focused on the synthesis of LPLs with an unsaturated chain, namely linoleoyl chain (Hong et al., 2011). Oleic acid has also been envisaged as an acyl donor for the esterification of GPA in comparison with lauric acid vinyl ester (Virto et al., 1999). In our laboratory, experiments have shown that oleoyl-LPC can be efficiently produced by direct esterification of GPC and free oleic acid.

Finally, the reaction parameters such as molar ratio of substrates, enzyme amount and reaction temperature markedly influence the catalytic activity of the lipase used. In optimized reaction conditions, high yields were obtained as claimed in above mentioned studies.

\section{Lipase-catalyzed alcoholysis of phospholipids}

Lipase-catalyzed alcoholysis of phospholipids has also been implemented in some studies for the preparation of LPLs. As an example, the reaction scheme for LPC synthesis is presented in Figure 5.

This approach was first developed in 1994 using Lipozyme IM-60 (immobilized lipase from $M$. miehei, Novozymes, Denmark) (Sarney et al., 1994). Other lipases tested were inactive in the conditions used. The initial phospholipid, namely synthetic dipalmitoyl phosphatidylcholine, was dissolved in $95 / 5 \mathrm{alcohol} /$ water. The alcohol therefore serves both as substrate of the reaction and as the liquid phase of the reaction medium. When ethanol, 2-propanol or 1-butanol were used, high conversion yields were achieved (>95\%) although no significant activity was detected with methanol. Interestingly, in these conditions, only 1-LPC was produced suggesting that no acyl migration occurred. Moreover the authors highlighted some advantages of alcoholysis vs. hydrolysis of phospholipids such as the homogeneous reaction mixture thus simplifying the overall process control and allowing continuous operation. 
Lipase-catalyzed alcoholysis of natural phospholipids from soybean was also investigated (Ghosh and Bhattacharyya, 1997) using Lipozyme IM-20 (immobilized lipase from M. miehei, Novozymes, Denmark) and various short- and long-chain alcohols $\left(\mathrm{C}_{4}\right.$ to $\left.\mathrm{C}_{18}\right)$. The aim of the authors was to simultaneously produce LPLs and fatty acid esters of individual alcohols, the latter having also important industrial applications. The reaction yields for both desired products were higher than $70 \%$ whatever the alcohol used.

More recently, Lipozyme TL-IM ${ }^{\circledR}$ and Novozym $435^{\circledR}$ were shown to catalyze ethanolysis of purified phosphatidylcholine as efficiently as Lipozyme RM-IM ${ }^{\circledR}$ (Yang et al., 2015). Reaction was carried out either directly in ethanol as in studies mentioned above or in hexane where phosphatidylcholine and ethanol were dissolved. In both systems, high LPC yields $(>90 \%)$ were reached with the three lipases tested, Novozym $435^{(\infty)}$ allowing the highest yields (about 98\%) with shorter reaction times ( $6 \mathrm{~h}$ and $4 \mathrm{~h}$ in ethanol and hexane, respectively).

\section{Conclusion}

Lipases have been shown to be efficient biocatalysts for LPL synthesis mainly via hydrolytic reactions or direct ester bond synthesis reactions. Interestingly, the substrates for lipase-catalyzed synthesis of LPLs such as vegetable lecithins for hydrolysis and GPC and free fatty acids for esterification, are easily available materials. Commercial lecithins are even by-products of the edible oil processing industry. Therefore, lipase-catalyzed methodologies for LPL synthesis are consistent with the concept of biomass biorefinery for the production of active molecules and ingredients widely developed nowadays.

Acknowledgements. This work was financially supported by "Laval Agglomération" and the "Conseil Général de la Mayenne".

\section{References}

Aura A-M, Forssell P, Mustranta A, Suortti T, Poutanen K. 1994. Enzymatic hydrolysis of oat and soya lecithin: effects on functional properties. J Am Oil Chem Soc 71: 887-891.

Bernoud N, Fenart L, Moliere P, et al. 1999. Preferential transfer of 2docosahexaenoyl-1-lysophosphatidylcholine through an in vitro blood-brain barrier over unesterified docosahexaenoic acid. $J$ Neurochem 72: 338-345.

Brkić L, Riederer M, Graier WF, Malli R, Frank S. 2012. Acyl chaindependent effect of lysophosphatidylcholine on cyclooxygenase (COX)-2 expression in endothelial cells. Atherosclerosis 224: 348-354.

Cabezas DM, Madoery R, Diehl BWK, Tomás MC. 2012. Emulsifying properties of different modified sunflower lecithins. $J$ Am Oil Chem Soc 89: 355-361.

Chen S, Li KW. 2007. Mass spectrometric identification of molecular species of phosphatidylcholine and lysophosphatidylcholine extracted from shark liver. J Agric Food Chem 55: 9670-9677.

Cmielewski P, Anson DS, Parsons DW. 2010. Lysophosphatidylcholine as an adjuvant for lentiviral vector mediated gene transfer to airway epithelium: effect of acyl chain length. Respir Res 11: 84. DOI: $10.1186 / 1465-9921-11-84$.
D'Arrigo P, Servi S. 2010. Synthesis of lysophospholipids. Molecules 15: $1354-1377$.

Devos M, Poisson L, Ergan F, Pencreac'h G. 2006. Enzymatic hydrolysis of phospholipids from Isochrysis galbana for docosahexaenoic acid enrichment. Enzyme Microb Technol 39: 548-554.

Fan L, Yin M, Ke C, et al. 2016. Use of plasma metabolomics to identify diagnostic biomarkers for early stage epithelial ovarian cancer. J Cancer 7: 1265-1272.

Farkas T, Kitajka K, Fodor E, et al. 2000. Docosahexaenoic acidcontaining phospholipid molecular species in brains of vertebrates. Proc Natl Acad Sci 97: 6362-6366.

Ghosh M, Bhattacharyya DK. 1997. Enzymatic alcoholysis reaction of soy phospholipids. J Am Oil Chem Soc 74: 597-599.

Grzelczyk A, Gendaszewska-Darmach E. 2013. Novel bioactive glycerol-based lysophospholipids: new data - new insight into their function. Biochimie 95: 667-679.

Gutiérrez-Ayesta C, Carelli AA, Ferreira ML. 2007. Relation between lipase structures and their catalytic ability to hydrolyse triglycerides and phospholipids. Enzyme Microb Technol 41: 35-43.

Haas M, Scott K, Jun W, Janssen G. 1994. Enzymatic phosphatidylcholine hydrolysis in organic solvents: an examination of selected commercially available lipases. J Am Oil Chem Soc 71: 483-490.

Han JJ, Rhee JS. 1995. Lipase-catalyzed synthesis of lysophosphatidic acid in a solvent free system. Biotechnol Lett 17: 531-536.

Han JJ, Rhee JS. 1998. Effect of salt hydrate pairs for water activity control on lipase-catalyzed synthesis of lysophospholipids in a solvent-free system. Enzyme Microb Technol 22: 158-164.

Hara F, Nakashima T, Fukuda H. 1997. Comparative study of commercially available lipases in hydrolysis reaction of phosphatidylcholine. J Am Oil Chem Soc 74: 1129-1132.

Haraldsson GG, Thorarensen A. 1999. Preparation of phospholipids highly enriched with $n-3$ polyunsaturated fatty acids by lipase. $J$ Am Oil Chem Soc 76: 1143-1149.

Hong SI, Kim Y, Kim C-T, Kim I-H. 2011. Enzymatic synthesis of lysophosphatidylcholine containing CLA from sn-glycero-3phosphatidylcholine (GPC) under vacuum. Food Chem 129: 1-6.

Hosokawa M, Ono M, Takahashi K, Inoue Y. 1998. Increase in deformability of human erythrocytes through the action of $\beta$-lysophospholipid rich in $n-3$ polyunsaturated fatty acid content. J Jpn Oil Chem Soc 47: 1313-1318.

Huang LS, Hung ND, Sok D-E, Kim MR. 2010. Lysophosphatidylcholine containing docosahexaenoic acid at the $s n-1$ position is anti-inflammatory. Lipids 45: 225-236.

Hung ND, Kim MR, Sok D-E. 2011. 2-Polyunsaturated acyl lysophosphatidylethanolamine attenuates inflammatory response in Zymosan A-induced peritonitis in mice. Lipids 46: 893-906.

Kapoor M, Gupta MN. 2012. Lipase promiscuity and its biochemical applications. Process Biochem 47: 555-569.

Kasinos M, Goñi ML, Nguyen MT, et al. 2014. Effect of hydrolysed sunflower lecithin on the heat-induced coagulation of recombined concentrated milk emulsions. Int Dairy J 38: 187-194.

Kim J, Kim BG. 1998. Lipase-catalyzed synthesis of lysophosphatidylcholine. Ann N Y Acad Sci 864: 341-344.

Kim J, Kim BG. 2000. Lipase-catalyzed synthesis of lysophosphatidylcholine using organic cosolvent for in situ water activity control. J Am Oil Chem Soc 77: 791-797.

Kim J, Lee CS, Oh J, Kim BG. 2001. Production of egg yolk lysolecithin with immobilized phospholipase A2. Enzyme Microb Technol 29: 587-592.

Koklic T, Trancar J. 2012. Lysolipid containing liposomes for transendothelial drug delivery. BMC Res Notes 5: 179. DOI: 10.1186/1756-0500-5-179. 
Lagarde M, Hachem M, Bernoud-Hubac N, Picq M, Véricel E, Guichardant M. 2015. Biological properties of a DHA-containing structured phospholipid (AceDoPC) to target the brain. Prostaglandins Leukot Essent Fat Acids 92: 63-65.

Lin M-E, Herr DR, Chun J. 2010. Lysophosphatidic acid (LPA) receptors: signaling properties and disease relevance. Prostaglandins Other Lipid Mediat 91: 130-138.

Ono M, Hosokawa M, Inoue Y, Takahashi K. 1997. Water activityadjusted enzymatic partial hydrolysis of phospholipids to concentrate polyunsaturated fatty acids. J Am Oil Chem Soc 74: $1415-1417$.

Pencreac'h G, Ergan F, Poisson L. 2013. DHA-lysophospholipid production. Curr Org Chem 17: 793-801.

Plückthun A, Dennis EA. 1982. Acyl andphosphoryl migration in lysophospholipids: importance in phospholipid synthesis and phospholipase specificity. Biochemistry (Mosc) 21: 1743-1750.

Poisson L, Devos M, Godet S, Ergan F, Pencreac'h G. 2009. Acyl migration during deacylation of phospholipids rich in docosahexaenoic acid (DHA): an enzymatic approach for evidence and study. Biotechnol Lett 31: 743-749.

Rao SP, Riederer M, Lechleitner M, et al. 2013. Acyl chain-dependent effect of lysophosphatidylcholine on endothelium-dependent vasorelaxation. PLOS ONE 8: e65155. DOI: 10.1371/journal. pone. 0065155 .

Riederer M, Ojala PJ, Hrzenjak A, et al. 2010. Acyl chain-dependent effect of lysophosphatidylcholine on endothelial prostacyclin production. J Lipid Res 51: 2957-2966.

Sarney DB, Fregapane G, Vulfson EN. 1994. Lipase-catalyzed synthesis of lysophospholipids in a continuous bioreactor. $\mathrm{J} \mathrm{Am}$ Oil Chem Soc 71: 93-96.
Stergiou P-Y, Foukis A, Filippou M, et al. 2013. Advances in lipase-catalyzed esterification reactions. Biotechnol $A d v$ 31: 1846-1859.

Tsushima T, Matsubara K, Ohkubo T, Inoue Y, Takahashi K. 2012. Docosahexaenoic- and eicosapentaenoic acid-bound lysophospholipids are more effective in suppressing angiogenesis than conjugated docosahexaenoic acid. J Oleo Sci 61: 427-432.

Valentine WJ, Fujiwara Y, Tsukahara R, Tigyi G. 2008. Lysophospholipid signaling: beyond the EDGs. Biochim Biophys ActaGen Subj 1780: 597-605.

Vikbjerg AF, Mu H, Xu X. 2005. Parameters affecting incorporation and by-product formation during the production of structured phospholipids by lipase-catalyzed acidolysis in solvent-free system. J Mol Catal B Enzym 36: 14-21.

Virto C, Adlercreutz P. 2000. Lysophosphatidylcholine synthesis with Candida antarctica lipase B (Novozym 435). Enzyme Microb Technol 26: 630-635.

Virto C, Svensson I, Adlercreutz P. 1999. Enzymatic synthesis of lysophosphatidic acid and phosphatidic acid. Enzyme Microb Technol 24: 651-658.

Yahagi S, Koike M, Okano Y, Masaki H. 2011. Lysophospholipids improve skin moisturization by modulating of calciumdependent cell differentiation pathway. Int $J$ Cosmet Sci 33: 251-256.

Yang G, Yang R, Hu H. 2015. Lysophosphatidylcholine synthesis by lipase-catalyzed ethanolysis. J Oleo Sci 64: 443-447.

Zhao Z, Xiao Y, Elson P, et al. 2007. Plasma lysophosphatidylcholine levels: potential biomarkers for colorectal cancer. J Clin Oncol 25: 2696-2701.

Cite this article as: Mnasri T, Hérault J, Gauvry L, Loiseau C, Poisson L, Ergan F, Pencréac'h G. 2017. Lipase-catalyzed production of lysophospholipids. OCL 24(4): D405. 